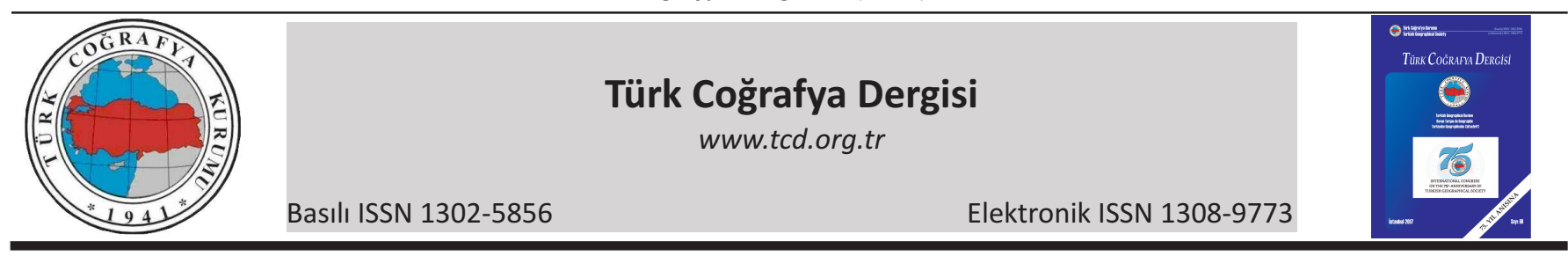

\title{
HadGEM2-ES/RegCM4.3.4 küresel/bölgesel model verilerine göre Kaz Dağı ve yakın çevresinin yağışlarında olası değişiklikler (2000-2099)
}

\author{
Possible changes in precipitation in Mount Ida (and vicinity) according to HadGEM2- \\ ES/RegCM4.3.4 global/regional model outputs (2000-2099)
}

\section{Berna Hepbilgin*a (D) Telat Koça (D)}

${ }^{a}$ Çanakkale Onsekiz Mart Üniversitesi, Fen-Edebiyat Fakültesi, Coğrafya Bölümü, Çanakkale.

\section{BILGi / INFO}

Geliş/Received: 26.04.2017

Kabul/Accepted: 27.07.2017

Anahtar Kelimeler:

iklim değişikliği

Yağış

RegCM4.3.4

HadGEM2-ES

\section{Keywords:}

Climate change

Precipitation

RegCM4.3.4

HadGEM2-ES

*Sorumlu yazar/Corresponding author (B. Hepbilgin)

bernahepbilgin@comu.edu.tr

http://doi.org/10.17211/tcd.309311

\begin{abstract}
ÖZ / ABSTRACT
İklim değişikliğinin doğal ve sosyal ortama yansımaları ve bu sorun üzerine çözüm arayışı çabaları gelişmektedir. Bu çabalar içerisinde iklim sisteminin gelecek dönemlerdeki zorlamalara nasıl tepkiler vereceğini öngörmek için kullanılabilen en iyi araç iklim modelleridir. Günümüzde çeşitli küresel iklim model çıktlarından dinamik ölçek küçültme yöntemi ile çözünürlüğü daha yüksek bölgesel model sonuçları elde edilmeye çalışıımaktadır. Türkiye'de de Meteoroloji Genel Müdürlüğü (MGM) tarafindan, Hükümetler Arası İklim Değişikliği Paneli'nin (IPCC) 5. Değerlendirme Raporu (AR5) kapsamındaki küresel iklim modelleri ve senaryo çıktıları ile iklim projeksiyonları bölge, havza ve il ölçeğinde uygulanmaktadır. Bununla birlikte Kazdağı yerel ölçeğinde herhangi bir yağış projeksiyonu çalışmasına ulaşılamamıştır. Konumu, özel topografyası, kuzey ve güney yamacında farklı iklim, doğal ve sosyal ortamları ile büyük öneme sahip olan Kazdağı'nın iklim değişikliğinden nasıl etkileneceği üzerine araştırma ihtiyacı hissedilmiştir. Bu çalışma Kazdağı'nın ikliminde ve buna bağlı olarak ağaç formasyonunun dağııışında 2000-2099 yılları arasındaki olası değişikliklerin tespitine yönelik devam eden doktora çalışmasının bir kısmını oluşturmaktadır. Bu çalışmada 1971-2000 dönemine ait ve MGM tarafindan HadGEM2-ES/RegCM4.3.4 küresel/bölgesel çıktılarıyla üretilmiş iki senaryoya ait (RCP4.5 ve RCP8.5), 2016-2040; 2041-2070 ve 2071-2099 dönemlerine ait yıllık ortalama toplam yağış anomali değerleri kullanılarak Kazdağı ve Yakın Çevresi'nde yağışlardaki olası değişiklikler ortaya konulmuştur. Dağılık topografyanın tüm yüzeyinde $10 \mathrm{~m} \times 10 \mathrm{~m}$ grid merkezlerinin yağış değerleri Coğrafi Bilgi Sistemleri programı yardımıyla hesaplanıp modellenerek sahanın yağı̧ analizleri yapılmış ve haritaları üretilmiştir. Bulgulara göre Kazdağı ve yakın çevresinde yağışlar her iki senaryo için de bu yüzyılın sonuna kadar önemli ölçüde artmaktadır.
\end{abstract}

Climate Change and the efforts of solution seeking on it are developing. Climate models are the best tools in these efforts to foresee how the climate system will react to the climatic forces. Climate models are to be downscaled using Dynamic Downscaling methods, These are efforts of getting both higher resolution and real-like output results. Also in Turkey, Climate projections are obtained via Global Climate Model Outputs which are in the scope of IPCC-AR5 and downscaled to regional and local with province scale. However, No projectional research was found at the scale of Mount Ida and vicinity. Thus, it is investigated in this paper that how Mount Ida, which has importance with different climate, natural and social environment both side of, and with special topography is influenced by Climate Change. This study forms a part of a PhD thesis which aimed at determination of possible changes of both climate and tree formation areas between 2000-2099 years. In this study, it is investigated the changes in annual mean precipitation in Mount Ida and its vicinity until the end of this century in periods of 2016-2040; 2041-2070 and 2071-2099 based on HadGEM2-ES/RegCM4.3.4 global/regional models' outputs both RCP4.5 and RCP 8.5 scenarios. Precipitation values of $10 \mathrm{~m} \times 10 \mathrm{~m}$ grid centre of surfaces of the mountainous area were calculated, analyzed and produced maps in GIS. According to findings, annual mean precipitation values in the area increase dramatically until the end of this century.

\section{Giriş}

İklim doğal, sosyal ve ekonomik hayat olumlu ve/veya olumsuz yönde etkileyebilmektedir. İklimin temel elemanı olan sıcaklıklardaki 20.yy ortalarından beri gözlenen küresel artışın ana ne- deninin çok yüksek olasılıkla insan olduğu Hükümetler Arası İklim Değişikliği Paneli IPCC (AR4) değerlendirme raporunda net bir şekilde ifade edilmiştir (Turp vd., 2014). İnsanların sosyal 
ve ekonomik etkinliklerini sorunsuz olarak sürdürebilmeleri için iklim değişikliğinin doğal ve beşeri ortama yıkıcı etkilerinin önceden saptanabilmesi ve bu doğrultuda önlemler alınması gerekmektedir. İklim değişikliklerini tespit üzerine en önemli çaba iklim değişikliği modelleme çalışmalarıdır (Demir vd., 2013). İklim değişikliği modelleme çalışmaları belirli senaryolara dayandırılır. Senaryo, olabileceği öngörülen olayların resmedilmesidir (Demir vd., 2013). Belirli bir bölgenin gelecekteki iklimi hakkında yorum yapılabilmesi, o bölgede meydana gelmesi muhtemel çevresel değişikliklerin de bilinmesini gerektirir. İklim modelleri ortam şartlarını beklenen değişimlere göre ayrıntılı şekilde yeniden kurgulama imkânı vermektedir. 2007 yılında yayımlanan Hükümetler Arası İklim Değişikliği Paneli (IPCC) 4. Değerlendirme Raporu'ndan bu yana gelişen teknolojik yapı sonucu IPCC 5. Değerlendirme raporu hazırlanmıştır (Demir vd., 2013). Bu rapora göre, iklim sistemindeki ısınma özellikle 1950'den sonra açık bir şekilde görülmektedir. Atmosfer ve okyanusların ısınması yanında, kalıcı kar örtüsünde ve buzullarda azalmalar, deniz seviyesinde yükselmeler ve sera gazı konsantrasyonlarında artışlar gözlenmektedir. Yağışlarda ise düzensizliğin artacağı, kurak ve ıslak periyotlar ile kurak ve ıslak alanlar arasındaki farkın açılacağı belirtilmektedir (Demircan vd., 2014).

Konumu, özel topografyası, kuzey ve güney yamacında farklı iklim, doğal ve sosyal ortamları ile büyük bir öneme sahip olan Kazdağı'nda yağışların iklim değişikliğinden nasıl etkileneceğinin bilinmiyor olması çalışmanın problemini oluşturmaktadır (Şekil 1). Bu çalışma ayrıca İklim Değişikliğinin Kazdağı ve Yakın Çevresinin İklimi ve Ağaç Formasyonu Dağılışına Olası Etkileri konusu üzerine yapılan doktora tezinin de bir kısmını oluşturmaktadır. Bu çalışmada Kazdağı çevresinden seçilen sekiz meteoroloji istasyonuna ait 1971-2000 referans dönemi yıllık ortalama toplam yağış değerleri ve HadGEM2-ES (iyimserRCP4.5 ve kötümser-RCP8.5) senaryolara ait bölgesel iklim modeli (RegCM4.3.4) üç döneme ait (2016-2040; 2041-2070; ve
2071-2099) yıllık ortalama yağış anomali değerleri kullanılmıştır. Böylece Kazdağı ve yakın çevresindeki yağışların yüzyılın sonuna kadar nasıl değişim göstereceğinin öngörüsü sağlanmışttr. Bu çalışmanın bulgu ve sonuçları öncelikle yüzyılın sonuna kadar sahanın yağış miktarlarındaki değişiklikleri ve bu değişikliklerin etkilerinin anlaşılmasını sağlayacaktır. İkinci olarak, bazı iklim indislerine uygulanarak sahanın iklim değişikliğinin analiz edilmesine temel oluşturacaktır. Son olarak, muhtemel iklim değişikliğiyle Kazdağı'ndaki ağaç formasyonunun dağılış alanlarındaki değişimin ortaya konulması ve değerlendirilmesine katkı sağlayacaktır.

Kazdağı, sahip olduğu çok çeşitli ve endemik türler ile zengin biyoçeşitliliğe sahiptir. Bunun yanında Akdeniz ve Karadeniz ikliminin geçiş hattında bulunmaktadır. Bundan dolayı kuzey ve güney yamacında iklim özellikleri birbirinden farklıdır. Güney yamaçta baskın olarak kurakçıl türler bulunur; fakat yamacın sahip olduğu topografik yapının özelliği olarak çok sayıda mikro iklim alanı doğmuştur. Bu nedenle güney yamaçta lokal olarak nemcil türlerin varlığı doğal ortamı zenginleştiren bir faktördür. Kazdağı'nın doruk kesiminde iklimsel geçiş türleri; kuzey yamacında ise kuzeyli hava kütlelerine açıklık nedeniyle daha nemcil türler bulunmaktadır. Bu itibarla, Kazdağı ve yakın çevresinde yıllık ortalama yağışlardaki olası değişikliklerinin tespit edilmesi önem arz etmektedir.

Gelecek dönemlere ait iklim projeksiyonları yapmak ve çeşitli zorlamalara karşı iklim sisteminin vereceği yanıt öngörmek için kullanılabilen en iyi araç çeşitli senaryolara göre geliştirilmiş iklim modelleridir. Senaryo, olması öngörülen olayın resmidir. RCP 4.5 bir denge senaryosudur ve sera gazı salımlarına yönelik tüm stratejik ve teknolojik önlemlerle 2100 yılına kadar toplam ışınımsal zorlamanın $4.5 \mathrm{~W} / \mathrm{m}^{2}$ değerine ulaşacağını ve daha sonrasında bu değerde kararlılık göstereceğini tasvir eder. RCP 8.5 ise sera gazı salımlarında sürekli bir artış temel alarak ışınımsal zorlamanın 2100 itibariyle $8.5 \mathrm{~W} / \mathrm{m}^{2}$ değerine ulaşaca-

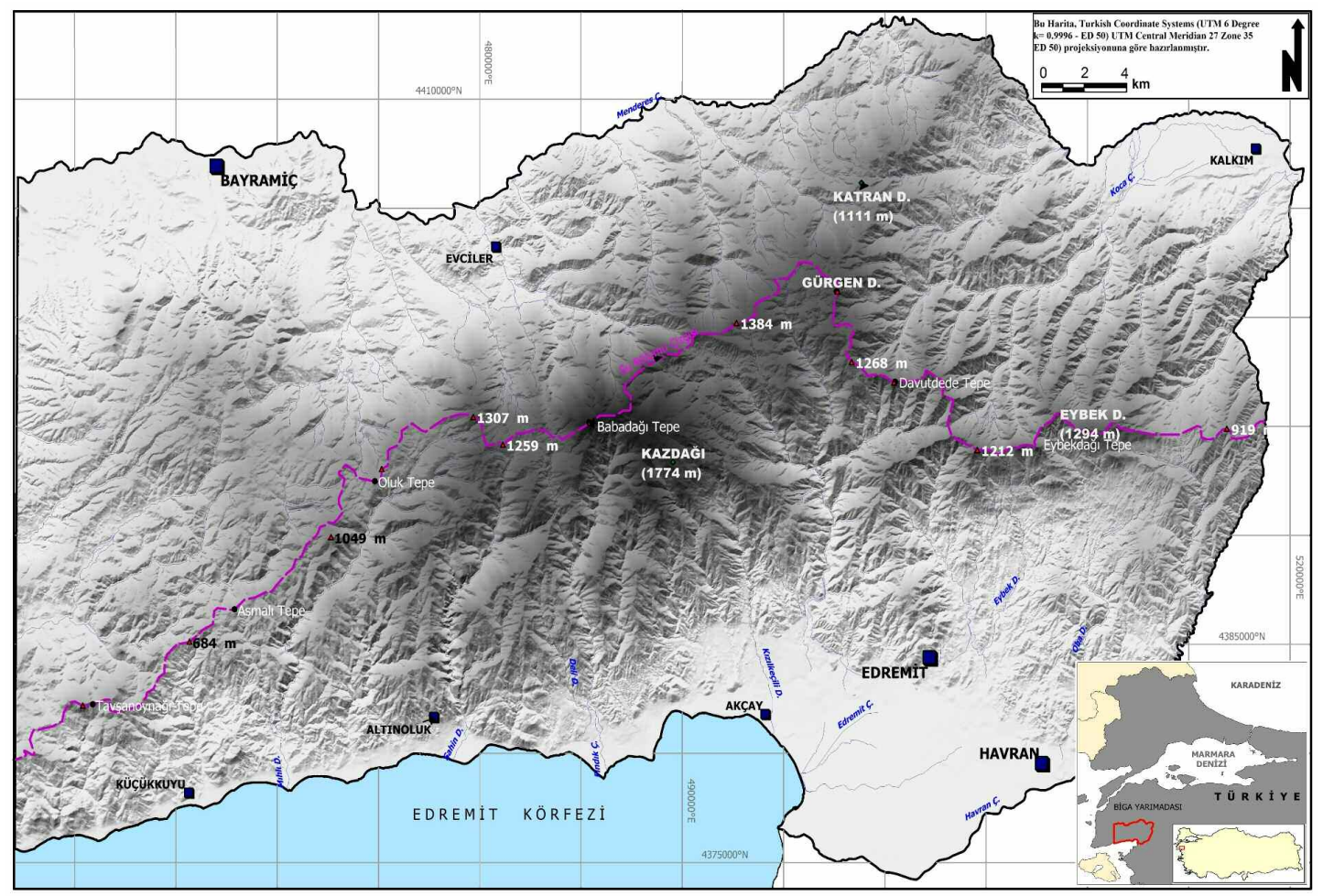

Şekil 1. Kazdağı ve yakın çevresinin lokasyon haritası.

Figure 1. Location map of Kazdağı (Mt.Ida) and vicinity. 
ğını karakterize eder (Turp vd. 2014).

Literatürde, yağışlardaki değişikliklerin zaman serisi analizleri ile tespit edildiği çalışmaların (örn. Türkeş 1996; Sarış 2006; Karabulut 2009; Gönençgil 2010; Ölgen 2010; Sarış vd.,2010; Bahadır 2011b; Türkeş ve Deniz 2011; Sütgibi 2015) yanı sıra, çeşitli mekânsal ve zamansal ölçeklerde olası yağış değişikliklerinin küresel ve bölgesel iklim modelleri entegre edilerek kestirimlerinin yapıldığı çok sayıda yerli ve yabancı yayına ulaşılmıştır (Tatlı 2004; Önol vd., 2009; Bahadır 2011a; Öztürk vd., 2011; Demir vd.,2013; Şen vd., 2013; Chou vd., 2014; Demircan vd.,2014a-b; Turp vd., 2014; Akçakaya vd., 2015; Babaeiana vd., 2015; Efe vd., 2015; Altnsoy vd., 2011; Lee vd., 2016; Gampe vd., 2016; Gürkan vd., 2016; Wang vd., 2016).

HadGEM2-ES küresel model çıktılarıyla bölgesel model çalıştrılan bir araşttrmada (Turp vd., 2014) Türkiye'nin büyük bir bölümünün yakın gelecekte günümüz klimatolojisine göre daha sıcak ve kurak bir iklimle karşı karşıya kalacağı; Akdeniz ikliminin egemen olduğu bölgelerin iklim değişikliğine ve olası sonuçlarına karşı açık ve hassas olduğu belirtilmiştir (Turp vd. 2014).

Türkiye'de günümüzden yüzyılın sonuna kadar sıcaklık farklarının artma, yağış farklarının ise azalma eğiliminde olduğu ve ülke genelinde bütün dönemlerin kış mevsimlerinde yağış artışı olacağı bir başka HadGEM küresel model ve bölgesel model çıktlarına dayanan çalışma bulgularında (Demircan vd., 2014) her iki senaryoda elde edilmiştir.

Akçakaya ve arkadaşlarının (2015) Türkiye'nin ortalama günlük yağış değerleri üzerine gerçekleştirdikleri bir projeksiyon araştırmasına göre (Akçakaya vd., 2015) Türkiye geneli ortalama en yüksek yağış artışının yaklaşık 180 mm; en fazla düşüşün yaklaşık 145 mm civarında olacağı öngörülmüştür. Yine aynı çalışmada 2071-2099 dönemi için yağışların yıllık 60 mm azalacağı beklenmektedir.

2013-2099 yılları arasında Türkiye genel yağış ortalamasının RCP 4.5 senaryosuna göre düştüğü, RCP 8.5 senaryosuna göre ise ilk dönemlerde artip son dönemlerde azaldığı; Marmara ve Kuzey Ege havzalarındaki yağışlarda ise her iki senaryoya göre de tüm dönemlerde artı̧lar olacağı belirtilmiştir (Demircan, vd., 2014; Akçakaya vd., 2015).

Marmara ve Ege bölgesinin yüksek kesimlerindeki yağışlarda (Demircan vd., 2014) 2013-2020 döneminde her iki senaryoya göre de $300 \mathrm{~mm}$ varan artş̧lar olacağı öngörülmüştür. RCP 4,5 senaryosuna göre 2031-2040 döneminde Marmara ve Ege bölgelerinin özellikle kıyı kesiminde 300 mm ye varan artş̧lar öngörülmektedir. RCP 8,5 senaryo çıktlarında normallerin üzerinde yağış beklentisinin alansal olarak daha fazla olduğu belirtilmiştir (Demircan, vd., 2014).

Marmara Havzasında önümüzdeki 85 yıllık süreçte (2015-2100) yağışlarda HadGEM modeli bulgularına göre özellikle kıyı bölgelerde ve 85 yılın çoğunluğunda pozitif anomali olduğu belirtilmiştir. Bu modelde her iki senaryoya göre 85 yılın çoğunluğunda toplam yağış değerlerinin 100 mm'yi aştığı ve Marmara havzasının daha nemli ve yağışlı döneme gireceği belirtilmiştir (IDSKE 2016).

\section{Yöntem ve Veri}

Bu çalışmada Kazdağı çevresindeki sekiz meteoroloji istasyo- nuna (Bergama, Ayvalık, Bozcaada, Burhaniye, Edremit, Balıkesir, Gönen, Çanakkale) ait 1971-2000 referans dönemi yıllık ortalama toplam yağış miktarı değerleri kullanılmıştır. Ayrıca RCP 4.5 ve RCP 8.5 (Representative Concentration Pathways -Temsili Konsantrasyon Yolu) senaryoları HadGEM2-ES küresel iklim modeli çıktlarıyla RegCM4.3.4 bölgesel iklim modeli çalıştırılarak 20kmx20km çözünürlükte elde edilmiş olan 2016-2040; 2041-2070 ve 2071-2099 dönemlerine ait yıllık anomali değerleri Meteoroloji Genel Müdürlüğü'nden temin edilerek kullanılmıştır (MGM). Yukarıda belirtilen istasyonların yıllık yağış miktarlarına gelecek üç dönemin anomali değerleri eklenerek istasyonların gelecek üç dönemdeki yağış değerleri elde edilmiştir. Deniz seviyesinden değişik yükseltilerde bulunan bu istasyonlara ait hesaplanan bu yeni yağış değerleri deniz seviyesine indirgenmiş ve CBS-Mapinfo Pro 2015 ortamında TIN yöntemi ile deniz seviyesi yüzeyine enterpole edilmiştir. Ardından, tüm topografya yüzeyine $10 \mathrm{mx} 10 \mathrm{~m}$ grid merkezlerinin yağış değerleri Schreiber formülü ${ }^{1}$ uygulanarak modellenmiştir. Böylece sahanın 2000, 2040, 2070 ve 2099 yıllarına ait yağış modelleri elde edilmiştir. Modellerin tümünün maksimum ve minimum yağış değerleri göz önünde bulundurularak $200 \mathrm{~mm}$ aralıklarla 7 yağış aralığı belirlenmiştir. Böylece üretilen öngörüsel yağış miktarlarında minimum değer referans dönemi (1971-2000) için 569 mm; maksimum değer ise 2071-2099 dönemi için $1771 \mathrm{~mm}$ olarak elde edilmiştir. Yağış haritaları bu aralıklara göre üretilmiş ve değerlendirilmiştir.

\section{Bulgular}

\subsection{RCP 4.5 Senaryosuna Göre Elde Edilen Bulgular}

Referans dönemi yağış haritası incelendiğinde (1971-2000) sahanın \%90'ı 600-1200 mm yağış almaktadır. 1000-1600 mm yağışların büyük kesiminin Kazdağı su bölümü çizgisi güneyinde yer aldığı görülür (Şekil 2).

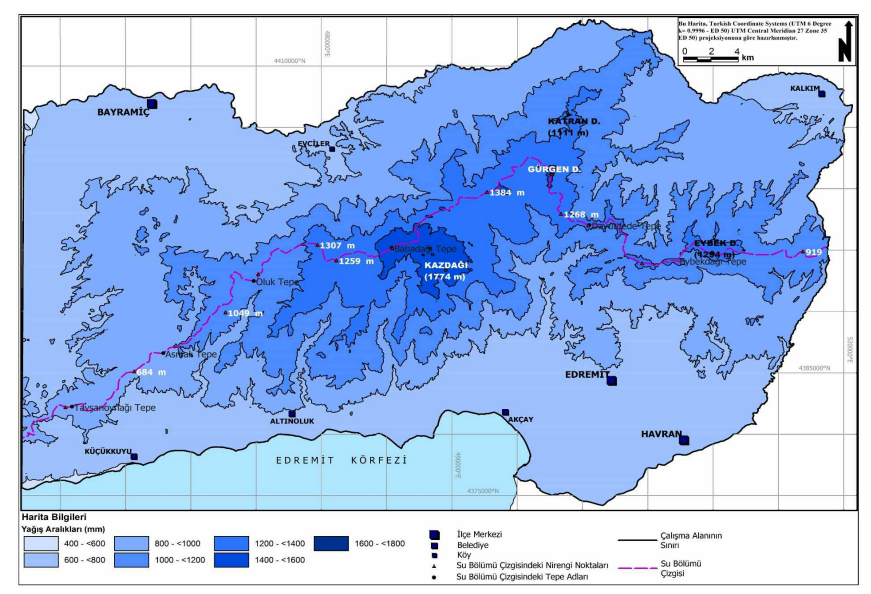

Şekil 2. Kazdağı ve yakın çevresinin 2000 Yılı (referans yıl) yıllık ortalama toplam yağış dağılışı haritası.

Figure 2. Distribution map of annual mean total precipitation in 2000 (reference year).

RCP 4.5 senaryo çıktılarından üretilen 2040 yılı olası yağış dağılış haritasına göre referans dönemdeki (1971-2000) 600-800 $\mathrm{mm}$ yağışlar Edremit ve çevresine; Edremit körfezi kıyı kesi-

${ }^{1}$ Schreiber formülü, $\mathrm{Ph}=\mathrm{Po} \pm 54 \mathrm{~h}$ şeklinde olup formülde; $\mathrm{Ph}=$ Dağda yükseltisi bilinen bir noktanın bulunacak yağış tutarı $(\mathrm{mm}), \mathrm{Po}=\mathrm{Dağ} \mathrm{eteğinde} \mathrm{yükseltisi} \mathrm{bilinen} \mathrm{ve} \mathrm{yağış} \mathrm{ra-}$ sadı yapan bir istasyonun yağış tutarı $(\mathrm{mm}), 54=$ Her 100 m yükseldikçe yıllık yağışın 54 $\mathrm{mm}$ arttğını gösteren katsayı ve $\mathrm{h}=$ Dağın eteğindeki istasyon ile yağıs miktarı bulunacak nokta arasındaki yükselti farkını (hektometre olarak) göstermektedir (Ardel, vd.,1969) 
mine; sahanın bat kesimindeki plato yüzeyi ve kuzey batıda Menderes çayı çevresine kadar genişlemiştir. 800-1000 mm yağış yağışlar ise Evciler ve Bayramiç'e kadar genişlemiştir. Kazdağı dorukları ve çevresinde 2040 yılında yağışlar 1600-1700 $\mathrm{mm}$ seviyelerine yükselmiştir (Şekil 3).

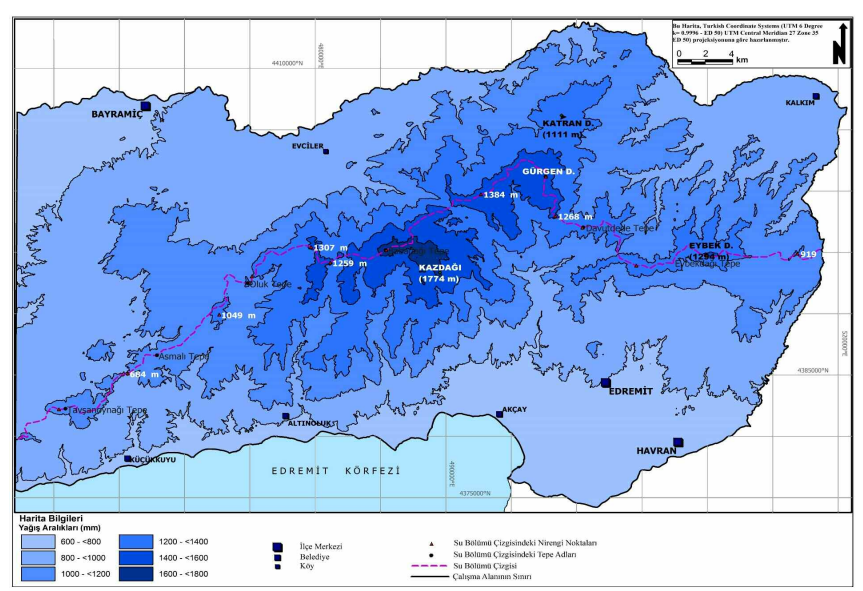

Şekil 3. RCP 4.5 senaryosuna göre Kazdağı ve yakın çevresinin 2040 yılı olası yağış dağııışı haritası.

Figure 3. Distribution map of possible annual mean precipitation in Mt.lda and vicinity in 2040 according to RCP 4.5.

2070 yılı olası yağış dağılış haritasında en çarpıcı değişim yine yüksek yağış değerlerindeki alansal genişlemedir. 2070 yılında kuzeyde Bayramiç ovasında yağış 800-1000 mm seviyelerine yükselmiştir. Kazdağı geniş doruk çevresinde, Gürgen ve Katran dorukları ve çevresinde, doğuda Eybek dağı ve çevresinde yağış 1600 mm'ye yükselmiştir. Kazdağı doruklarında ise yağış 1700 $\mathrm{mm}$ seviyesini geçmiştir (Şekil 4).

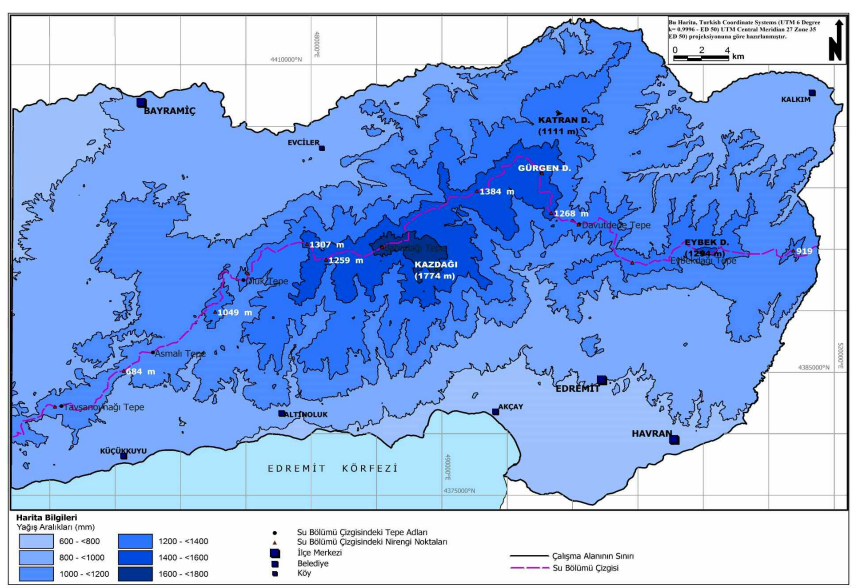

Şekil 4. RCP 4.5 senaryosuna göre Kazdağı ve yakın çevresinin 2070 yılı olası yağış dağılışı haritası.

Figure 4. Distribution map of possible annual mean precipitation in Mt.Ida and vicinity in 2070 according to RCP 4.5.

2099 yılı olası yağış dağılış haritasında kuzeyde Bayramiç, güneyde Edremit ovalarında yağışların 800-1000 mm seviyesine yükseldiği görülür. Kazdağı doruk çevresi, Gürgen, Katran ve Eybek dağlarında 1400-1600 mm seviyelerindeki yağış alanları genişlemiştir. Kazdağı doruklarında yağış 1800 mm seviyesine yükselmiştir (Şekil 5).

RCP 4.5 senaryosuna göre 2000, 2040, 2070 ve 2099 yağış grafikleri incelendiğinde, $600-800 \mathrm{~mm}$ yağış alanı yüzyılın sonuna kadar 645 km²'den 13 km²'ye düşmüş, 632 km²'lik alanın yağış miktarı yükselerek 800-1000 mm seviyelerine dönüşmüştür. Diğer yüksek yağış alanlarında ise sürekli genişleme olduğu göz- lenir. 2000-2099 yılları arasında 600-800 mm yağışlar azalırken etkilediği alan $631 \mathrm{~km}^{2}$ daralmıştir. Diğer taraftan, 800-1000 $\mathrm{mm}$ yağışlar 85 km², 1000-1200 mm yağışlar 292 km², 12001400 mm yağışlar 142 km², 1400-1600 mm yağışlar 99.6 km², $1600-1800 \mathrm{~mm}$ yağışlar ise $17.6 \mathrm{~km}^{2}$ alan kazanmıştır (Şekil 6).

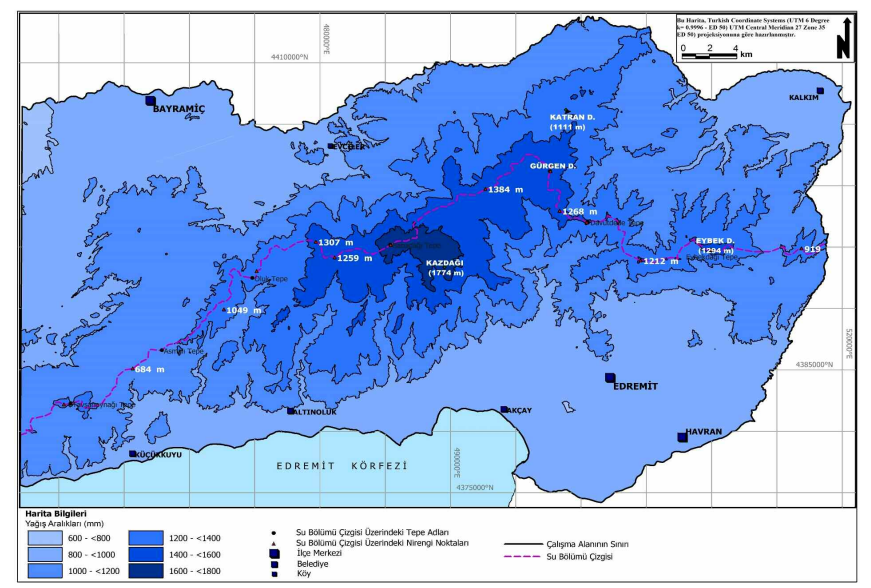

Şekil 5. RCP 4.5 senaryosuna göre Kazdağı ve yakın çevresinin 2099 yılı olası yağış dağılışı haritası.

Figure 5. Distribution map of possible annual mean precipitation in Mt.lda and vicinity in 2099 according to RCP 4.5 .
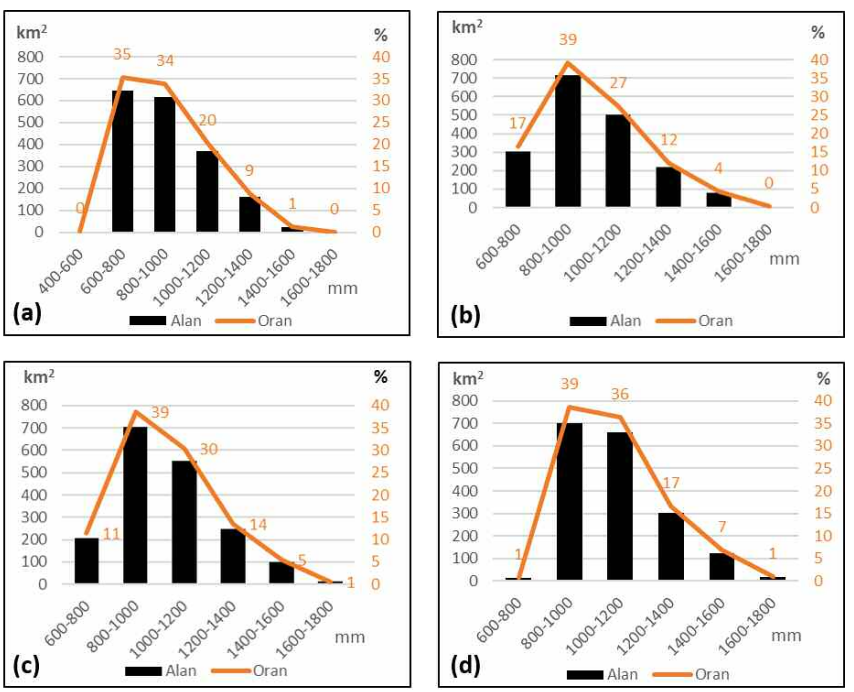

Şekil 6. a) Referans yılı (2000) yıllık toplam yağış dağılış grafiği, b) RCP 4.5 senaryosuna göre 2040 yılında olası yağışların alansal dağılış grafiği, c) RCP 4.5 senaryosuna göre 2070 yılında olası yağışların alansal dağılış grafiği, d) RCP 4.5 senaryosuna göre 2099 yılında olası yağışların alansal dağılış grafiği.

Figure 6. a) Distribution graph of annual mean precipitation according to reference year (2000), b) Areal distribution graph of possible precipitation in 2040 (RCP4.5), c) Areal distribution graph of possible precipitation in 2070 (RCP4.5), d) Areal distribution graph of possible precipitation in 2099 (RCP4.5).

RCP 4,5 senaryosuna göre yağışların alansal değişim ve değişim yüzdeleri incelenirse 2040 yılından itibaren sahada en düşük yağışlar 600-800 mm'dir. 1000-1800 mm arası yağışlarda ve bu yağışların sahada etki ettiği alanlarda önemli ölçüde artş ve genişleme gözlenir (Tablo 1 ).

2041-2070 ve 2071-2099 dönemlerinde 1000 mm'den düşük yağışlarda önemli ölçüde azalma, bu değerden yüksek yağışlarda artı̧̧ar gözlenir (Tablo 1).

\subsection{RCP 8.5 Senaryosuna Göre Elde Edilen Bulgular}

RCP 8,5 senaryosuna göre 2040 yılı olası yağış dağılışı haritasında 800-1000 mm arası yağışların sahada baskın ve en geniş 
Tablo 1. Referans yıl (2000) ve RCP 4.5 senaryosuna göre 2040, 2070 ve 2099 yıllarındaki olası yağış dağılış alanları ve değişim oranları.

Table 1. Possible precipitation areas and change rates in Mt. Ida and vicinity in 2040, 2070 and 2099 years according to RCP 4.5 scenario and reference year (2000).

\begin{tabular}{|c|c|c|c|c|c|c|c|c|}
\hline \multicolumn{9}{|c|}{ RCP 4.5} \\
\hline $\begin{array}{c}\text { Yağış Aralığı } \\
(\mathrm{mm})\end{array}$ & $\begin{array}{c}2000 \text { Yilı } \\
\text { Alan }\left(\mathbf{k m}^{2}\right)\end{array}$ & $\begin{array}{c}2040 \text { Yilt } \\
\text { Alan }\left(\mathrm{km}^{2}\right)\end{array}$ & $\begin{array}{c}2016-2040 \\
\text { A.D. (\%) }\end{array}$ & $\begin{array}{c}2070 \text { Yilt } \\
\text { Alan }\left(\mathrm{km}^{2}\right)\end{array}$ & $\begin{array}{c}2041-2070 \\
\text { A. D. (\%) }\end{array}$ & $\begin{array}{c}2099 \text { Yilı } \\
\text { Alan }\left(\mathrm{km}^{2}\right)\end{array}$ & $\begin{array}{l}2071-2099 \\
\text { A. D. }(\%)\end{array}$ & $\begin{array}{r}2000-2099 \\
\text { A.D. }(\%)\end{array}$ \\
\hline $400-600$ & 5.0 & - & - & - & - & - & - & \\
\hline $600-800$ & 644.9 & 303.4 & -53.0 & 207.9 & -31.5 & 13.1 & -93.7 & -98.0 \\
\hline $800-1000$ & 617.4 & 715.6 & 15.9 & 703.4 & -1.7 & 702.6 & -0.1 & 13.8 \\
\hline $1000-1200$ & 370.5 & 500.2 & 35.0 & 554.4 & 10.8 & 662.0 & 19.4 & 78.7 \\
\hline $1200-1400$ & 160.9 & 219.6 & 36.5 & 248.3 & 13.0 & 303.4 & 22.2 & 88.6 \\
\hline $1400-1600$ & 25.5 & 77.9 & 205.5 & 99.0 & 27.1 & 125.6 & 26.8 & 392.2 \\
\hline $1600-1800$ & 0.1 & 7.4 & 7561.8 & 11.2 & 50.6 & 17.6 & 56.7 & 17982.5 \\
\hline
\end{tabular}

alana sahip olduğu görülür. Bu alan kuzeyde Evciler'e, güneyde Edremit'e kadar sokulmuştur. Kazdağı doruk çevresinde, Eybek, Katran ve Gürgen dağlarında yağışlar 1200-1400 mm seviyelerine yükselmiştir (Şekil 7).

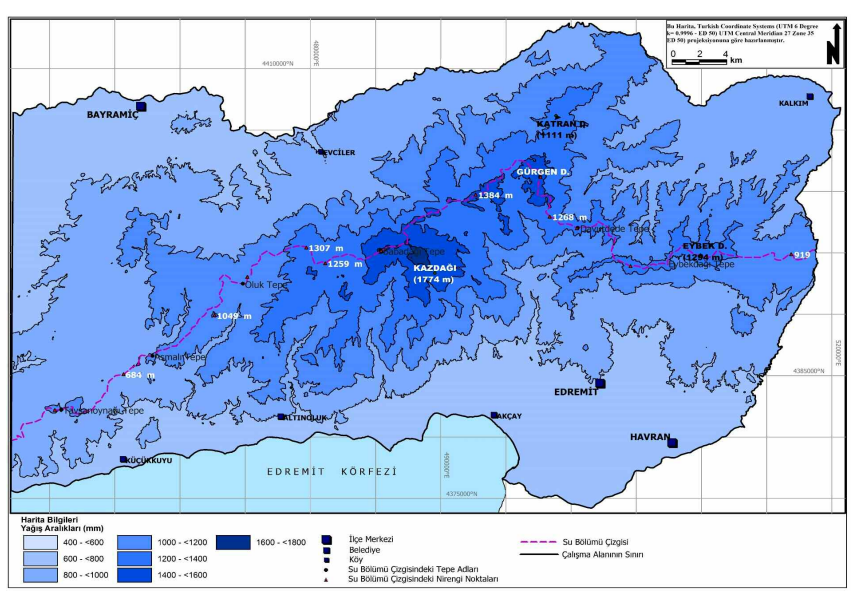

Şekil 7. RCP 8.5 senaryosuna göre Kazdağı ve yakın çevresinin 2040 yılı olas yağış dağılışı haritası.

Figure 7. Distribution map of possible annual mean precipitation in Mt.Ida and vicinity in 2040 according to RCP 8.5.

2070 yılı olası yağış dağılışı haritasında Kazdağı doruk çevreleri ve Gürgen dağında yağışlar 1400-1600 mm; Kazdağı doruklarında ise 1700 mm seviyesindedir (Şekil 8). Sahanın 2070 yılı olası yağış haritasında her iki senaryoda da sahanın büyük kısmı 800-1200 mm arasında yağış almaktadır. Sahada yağışlar arttı̆̆ için 1000-1800 mm yağış alanlarının genişlediği gözlenir (Şekil $4,8)$.

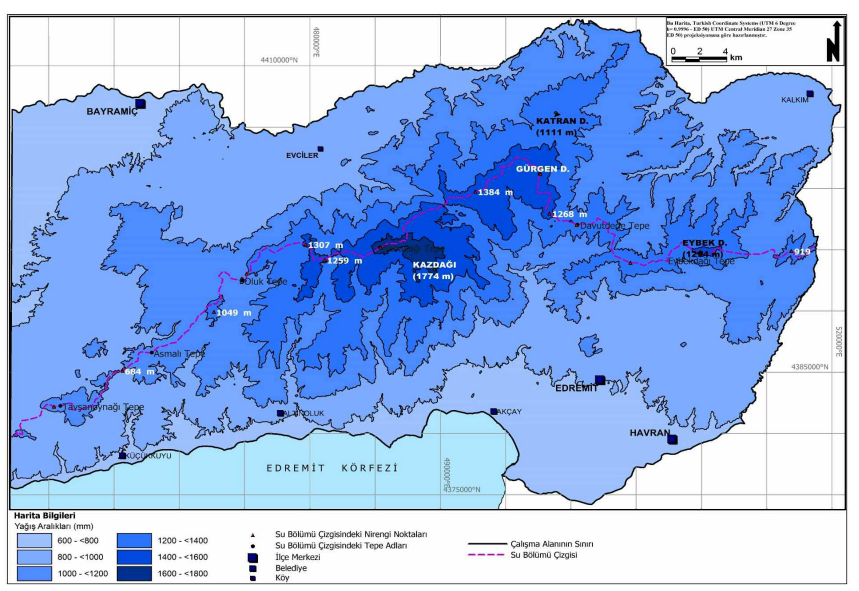

Şekil 8. RCP 8.5 senaryosuna göre Kazdağı ve yakın çevresinin 2070 yılı olası yağış dağılışı haritası.

Figure 8. Distribution map of possible annual mean precipitation in Mt.Ida and vicinity in 2070 according to RCP 8.5.

2099 yılı olası yağış dağılışı haritasına göre sahadaki en düşük yağışlar 600-800 mm aralığındadır (Şekil 9).

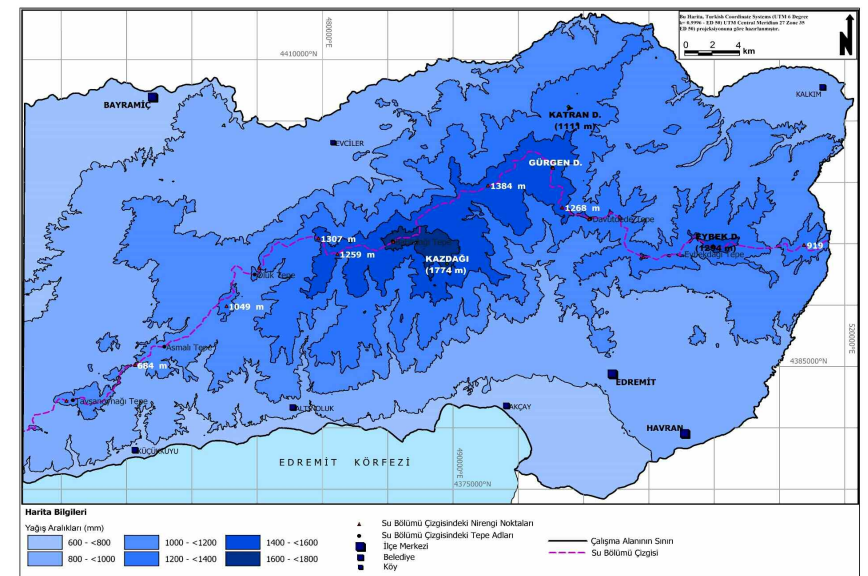

Şekil 9. RCP 8.5 senaryosuna göre Kazdağı ve yakın çevresinin 2099 yılı BGRB yağış dağılışı haritası.

Figure 9. Distribution map of possible annual mean precipitation in Mt.lda and vicinity in 2099 according to RCP 8.5.

8,5 senaryosuna göre yağışlardaki alansal değişim ve değişim yüzdeleri incelendiğinde 2040 itibariyle sahanın minimum yağış aralığı 600-800 mm'dir. Bununla birlikte bu yağış aralığı 2099 yılına doğru tüm dönemlerde sürekli daralmaktadır (Tablo 2). 800-1000 mm yağışlarda 2040 yılına kadar artı̧ ve alansal genişleme, sonraki dönemlerde azalma ve alansal daralma gözlenir. Sahada 1000-1800 mm arası yağış miktarlarında 2099 yılına kadar sürekli artı̧̧ ve sürekli alansal genişleme görülmektedir. 2070 yılına kadar yağış değişim oranlarında artış yönündeki sürekli değişimin, 2071-2099 döneminde önemli ölçüde düştüğü gözlenir (Tablo 2).

RCP 8.5 senaryosuna göre 2000, 2040, 2070 ve 2099 yağış grafikleri incelendiğinde, 2000 yılı grafiğinde sahanın yaklaşık olarak \%65'i 600-800 ve 800-1000 mm seviyelerinde yağış alırken, 2099 yılına gelindiğinde en yüksek yağışların 800-1000 ve 10001200 mm olduğu görülür (Şekil 10). 600-800 mm arası yağışla-

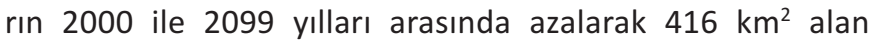
kaybettiği gözlenmektedir. 800-1800 mm yağışları kapsayan aralıklarda ise sırasıyla $60 \mathrm{~km}^{2}, 156 \mathrm{~km}^{2}, 113 \mathrm{~km}^{2}, 79 \mathrm{~km}^{2}$ ve 11 $\mathrm{km}^{2}$ yağış artışlarının ortaya çıktığı görülmektedir (Tablo 2).

\section{Tartışma ve Sonuç}

İklim Değişikliğinin Kazdağı ve Yakın Çevresindeki Ağaç Formasyonun Dağılışına Olası Etkilerinin Modellenmesi konulu doktora tezinin bir kısmı niteliğindeki bu çalışmada Kazdağı ve yakın çevresinde iklimin temel elemanlarından biri olan yağışın belirlenen aralıklarda yüzyılın sonuna kadar olası alansal ve oransal değişimi analiz edilmiştir.

HadGEM2-ES küresel modeli ve RegCM4.3.4 bölgesel model anomali değerlerine dayandırılan bu çalışmada 2099 yılına 
Tablo 2. Referans yıl (2000) ve RCP 8.5 senaryosuna göre 2040, 2070 ve 2099 yıllarındaki olası yağış dağılış alanları ve değişim oranları.

Table 2. Possible precipitation areas and change rates in Mt. Ida and vicinity in 2040, 2070 and 2099 years according to RCP 8.5 scenario and reference year (2000).

\begin{tabular}{|c|c|c|c|c|c|c|c|c|}
\hline \multicolumn{9}{|c|}{ RCP 8.5} \\
\hline $\begin{array}{c}\text { Yağış Aralı̆ı̆ı } \\
(\mathrm{mm})\end{array}$ & $\begin{array}{c}2000 \text { Yill } \\
\text { Alan }\left(\mathrm{km}^{2}\right)\end{array}$ & $\begin{array}{c}2040 \text { Yilt } \\
\text { Alan }\left(\mathrm{km}^{2}\right)\end{array}$ & $\begin{array}{c}2016-2040 \\
\text { A.D. (\%) }\end{array}$ & $\begin{array}{c}2070 \text { Yil } \\
\text { Alan }\left(\mathrm{km}^{2}\right)\end{array}$ & $\begin{array}{l}2041-2070 \\
\text { A. D. (\%) }\end{array}$ & $\begin{array}{c}2099 \text { Yilı } \\
\text { Alan }\left(\mathrm{km}^{2}\right)\end{array}$ & $\begin{array}{l}2071-2099 \\
\text { A. D. (\%) }\end{array}$ & $\begin{array}{c}2000-2099 \\
\text { A.D. (\%) }\end{array}$ \\
\hline $400-600$ & 5.0 & 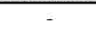 & - & - & - & - & - & - \\
\hline $600-800$ & 644.9 & 461.3 & -28.5 & 281.4 & -39.0 & 228.4 & -18.8 & -64.6 \\
\hline $800-1000$ & 617.4 & 694.3 & 12.5 & 683.1 & -1.6 & 677.6 & -0.8 & 9.8 \\
\hline $1000-1200$ & 370.5 & 436.0 & 17.7 & 520.5 & 19.4 & 526.3 & 1.1 & 42.1 \\
\hline $1200-1400$ & 160.9 & 187.6 & 16.6 & 242.5 & 29.3 & 274.7 & 13.3 & 70.7 \\
\hline $1400-1600$ & 25.5 & 42.6 & 67.1 & 87.8 & 106.0 & 105.6 & 20.2 & 314.0 \\
\hline $1600-1800$ & 0.1 & 2.5 & 2434.5 & 8.8 & 257.3 & 11.6 & 32.2 & 11872.8 \\
\hline
\end{tabular}
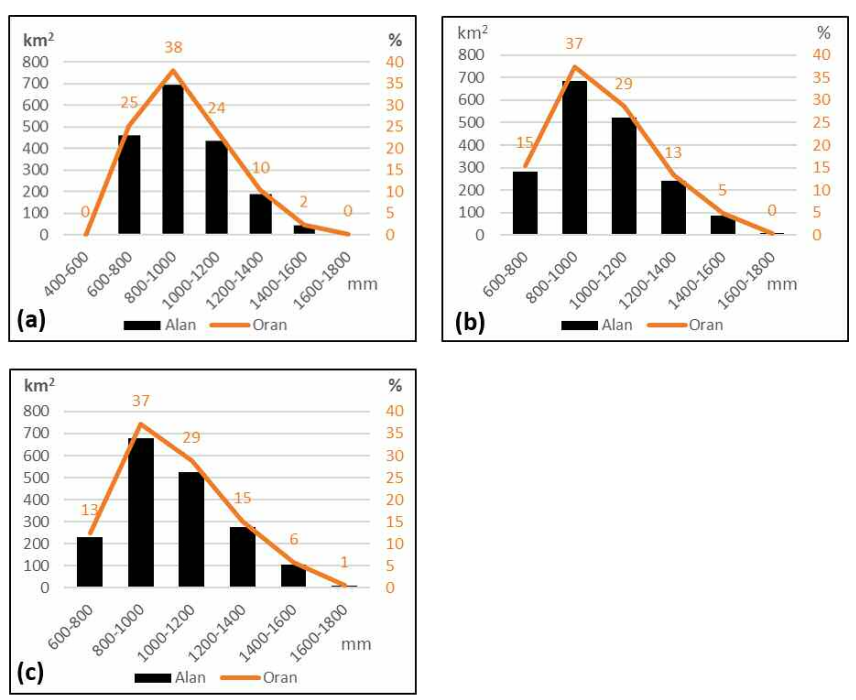

Şekil 10. a) RCP 8.5 senaryosuna göre 2040 yılında olası yağışların alansal dağılış grafiği, b) RCP 8.5 senaryosuna göre 2070 yılında olası yağışların alansal dağılış grafiği, c) RCP 8.5 senaryosuna göre 2099 yılında olası yağışların alansal dağılış grafiği.

Figure 10. a) Areal distribution graph of possible precipitation in 2040 (RCP8.5), c) Areal distribution graph of possible precipitation in 2070 (RCP8.5), d) Areal distribution graph of possible precipitation in 2099 (RCP8.5).

kadar Kazdağı ve yakın çevresinde yıllık ortalama toplam yağışlarda artı̧lar öngörülmüştür.

RCP 4.5 senaryosuna göre 2000 ve 2099 yıllarına ait olası yağış dağılış haritaları kıyaslandığında sahada yağışların 200-400 mm aralığında artth̆̆ı söylenebilir (Şekil 5-2).

Referans yılında (2000) sahada 600-1000 mm arası yağışlar en geniş alan kaplarken her iki senaryoya göre de tüm dönemlerde 800-1200 mm arası yağışlar en geniş alan kaplamaktadır (Şekil $2,5,10)$.

RCP 4.5 senaryosuna ait değişim oranları incelendiğinde (Tablo 1) yağış aralıklarındaki değişim ile ilgili iki çarpıcı sonuç şöyledir: Yağışlar dönemler sürecinde önemli oranda artmıştır. Sahada 2040 yılından itibaren 400 mm'den az yağış; 2099 yılında ise 600 mm'den az yağış görülmemektedir. 2000 yılında Kazdağı ve yakın çevresinde yaklaşık 645 km²'lik bir alanı $600-800 \mathrm{~mm}$ arası yağışlar etkilerken 2099 yılında 800 mm'den az yağışların etkin olduğu alan sahanın yalnızca 13 km²'lik bir kısmına karşılık gelmektedir. $1000 \mathrm{~mm}$ ve üzeri yağışlarda 2099 yılında \%78 ve üzeri oranlarda artışlar öngörülmüştür. RCP 8.5 senaryosuna ait değişim oranları tablosuna göre (Tablo 2 ) ise, oranlar daha düşük olmakla birlikte değişimin seyrinin yağış aralıkları için RCP 4.5 bulgularına paralel olduğu görülmektedir.

Küresel ve bölgesel modellerden öngörülerin elde edildiği önceki çalışmalardaki bulgular değerlendirildiğinde, Marmara ve Kuzey Ege havzalarında genel yağış ortalamasında tüm dönem- lerde beklenen artış öngörüsü (Akçakaya vd., 2015; Demircan vd., 2014) bu çalışmanın bulgularını desteklemektedir. Yine Marmara ve Ege bölgelerinin yüksek kesimlerindeki yağışlarda 300 mm'ye varan artş öngörüsü (Demircan vd., 2014) bulgularımızı desteklemektedir. Bununla birlikte 2013-2050 yılları arasında yıllık ortalama toplam yağışlarda azalan bir eğilim, (Efe vd., 2015:1) 1960-2010 referans verilerine göre, ülkenin kuzeyinde artış, GD Anadolu, Akdeniz ve Ege bölgelerinde azalış eğilimi olduğu belirtilmiştir. Şen ve arkadaşları (2015) çalışmalarında, Türkiye'nin güney ve bat kesimleri için \%30 yağış azalması öngörüsü elde etmişlerdir. IPCC Türkiye- iklim gözlem raporunda (2014) ise Türkiye'de yağışların ülkenin batısında azaldığı; kuzeyinde sonbahar mevsiminde arttğı ve yağışların \%20 üzerinde azaldığı belirtilmiştir. Bu bilgiler ile bu çalışmanın bulguları paralellik göstermemektedir. Meteoroloji Genel Müdürlüğü ilgili birimi tarafindan HadGEM2-ES modelinden bölgesel model çalıştrılarak elde edilen ve bu çalışmaya temel olan anomali değerlerinin pozitif anomali göstermektedir. Bununla birlikte aynı araştırmada kullanılan diğer küresel modellerden (MPI-ESM-MR ve GFDL-ESM2M) elde edilen çıktilar negatif anomaliler sunmaktadır.

Su Yönetimi Genel Müdürlüğü'nün Kuzey Ege havzası raporu (IDSKE, Ek-6, 2016) HadGEM2-ES modeli yıllık yağış değerlendirmelerine göre, Kuzey Ege havza geneli için toplam yağışlarda ilk yıllarda genellikle artış, sonrasında önemli düşüşler, 2040 yılına kadar Ege kıyılarında artış olacağı belirtilmiştir.

Aynı modelin RCP 4.5 senaryosuna göre, 2020 yılına kadar tüm Kuzey Ege havzasında toplam yağışta ciddi bir azalma beklenirken, RCP 8.5 senaryosuna göre yağış değerlerinin artacağı, RCP 4,5 senaryosuna göre $2015-2100$ yılları arasında toplam yağış miktarlarında yer yer artış ve azalmalar öngörülmektedir. Havzanın kuzey ve kuzeybatısında toplam yağış değerlerinin belirgin bir biçimde arttğı ve 2040 yılına kadarki dönem sonunda yıllık 200-250 mm artış değerlerine ulaştı̆̆ öngörülmektedir. 2040 ve sonrasında artş̧ın yüksek olmadığı belirtilmiştir. Bu bulgular bu araştırmanın bulgularını desteklemektedir. Kuzey Ege havzasının kuzey kesimlerinde 2050 yılı ve sonrasında toplam yağış değerlerinin yıllık 150-200 mm kadar azaldığı öngörülmektedir. Bahsedilen alan çalışma alanının bir kısmını kapsamaktadır bununla birlikte bu sonuç bulgularımız ile uyuşmamaktadır. Bulgularımıza göre tüm dönemlerde yağışlarda artş̧lar elde edilmiştir.

Su Yönetimi Genel Müdürlüğü'nün Marmara Havzası Raporu'nda (IDSKE, Ek-4, 2016) her iki senaryoya göre de (RCP 4.5 ve 8.5) havzanın yıllık yağışlarında belirgin artş̧ eğilimi belirtilmekle birlikte bu artş̧ların havzanın kuzey kesiminde dikkat çekici biçimde artacağı öngörüsü elde edilmiştir, bulgularımızı desteklemektedir.

Bu çalışmada 2000 yılı referans olmak üzere 2040, 2070 ve 
2099 yılında yıllık ortalama toplam yağışlarındaki olası değişiklikler incelenmiştir. Kazdağı ve yakın çevresi için mevsimlik yağış anomalileri temel alınarak yağışlardaki olası değişikliklerin mevsimsel açıdan analizi Kazdağı iklim değişikliği tespit çalışmalarında daha ayrıntılı öngörü sağlayacaktır.

İklim değişikliğinin doğal ve beşeri kaynaklara etkilerinin tespiti konusunda daha yerel ölçekli ve yüksek çözünürlüklü modelleme çalışmaları önem arz etmekte ve bu konuda daha küçük alanlarda iklim değişikliğinin etkilerinin gerçeğe yakın tespitlerine ihtiyaç duyulmaktadır. Kazdağı ve yakın çevresi ölçeğinde Coğrafi Bilgi Sistemleri yardımıyla yapılan, yıllık ortalama toplam yağışların 2099 yılına kadar değişimini kapsayan bu çalışma bu çabalara bir örnek teşkil etmektedir. Yapılan bu çalışma farklı enterpolasyon teknikleri ve başka değişkenler de dikkate alınarak geliştirilebilir. Türkiye üzerine yapılan bölgesel yağış modellerinde özellikle dağlık topografyanın etkisinin yüksek olduğu kesimlerde, örneğin Kafkaslar gibi, yağış miktarlarında gelecek dönemler için artş olacağı öngörülmüştür (Turp vd. 2014: 15). Bununla birlikte deniz seviyesinden 12 km gibi kısa bir mesafede 1774 m. yükseltiye ulaşan Kazdağı gibi dağlık topografyalarda yağışları gerçeğe yakın modelleyebilmek zorluk teşkil etmektedir. Bununla birlikte son dönemde Türkoğlu ve arkadaşlarının (2016) çalışmaları gibi yağışları dağlık alanlarda gerçeğe daha yakın modelleyebilmek için değişik yöntemler geliştirilmektedir. Bu yöntemlerin kullanımda yaygınlaşmasıyla enterpolasyonda değişkenlerin sayısı da arttılırak çalışmanın daha başarılı yağış değişikliği modellemeleri ile geliştirilebileceği düşünülmektedir.

\section{Katkı Belirtme}

Bu çalışma Çanakkale Onsekiz Mart Üniversitesi Bilimsel Araştırma Projeleri Koordinasyon Birimi tarafindan desteklenen doktora tezinden üretilmiştir (Proje No: 877). Desteklerinden dolayı Çanakkale Onsekiz Mart Üniversitesi Bilimsel Araştirmalar Projeleri Birimine teşekkür ederiz.

\section{Kaynakça}

Akçakaya, A., Sümer, U. M., Demircan, M., Demir, Ö., Atay, H., Eskioğlu, O., Gürkan, H., Yazıcı, B., Kocatürk, A., Şensoy, S., Bölük, E., Arabacı, H., Açar, Y., Ekici, M., Yağan, S., Çukurçayır, F. (2015) Yeni Senaryolar ile Türkiye İklim Projeksiyonları ve İklim Değişikliği. T.C. Orman ve Su İşleri Bakanlığı, Araştırma Dairesi Başkanlığı, Klimatoloji Şube Müdürlüğü, Ankara.

Altınsoy H. Öztürk, T., Türkeş, M, Kurnaz M.L. (2011) “Küresel İklim Model Kullanılarak Akdeniz Havzası'nın Gelecek Hava Sıcaklığı ve Yağış Değişikliklerinin Kestirilmesi" Türk Coğrafya Kurumu, Uluslar arası katılımlı Ulusal Coğrafya Kongresi Bildiri Dokümanı, s.7-10 Sep.2011.

Ardel, A., Kurter, A., Dönmez, Y. (1969) Klimatoloji Tatbikat. İstanbul Üniversitesi Yayınları No:1123 Taş Matbaası, İstanbul

Babaeiana, I., Modiriana, R., Karimian, M., Zarghamib, M. (2015) "Simulation of climate change in Iran during 2071-2100 using PRECIS regional climate modelling system" Desert 20/2 pp:123-134

Bahadır, M. (2011a) “Türkiye'de İklim Değişikliği'nin İklim Bölgelerine Yansımasında Kuzey-Güney Yönlü Sıcaklık ve Yağış Değişim Öngörüleri" Türk Dünyası Araştırmaları Vakfi, Akademik Bakış Dergisi (26) Eylül-Ekim s.1-18

Bahadır, M. Özdemir, M. A. (2011b) “Acıgöl Havzası'nda Yağışın Trend Analizi ve Haritalanması". Türk Coğrafya Dergisi, 57 s.33-42

Chou, S.C., Lyra, A., Mourao, C., Dereczynski, C., Pilotto, Gomes, J.,
Bustamante, J., Tavares, P., Silva, A., Rodrigues, A., Compos, D., Chagas, D., Sueiro, G., Siqueira, G., Marengo, J. (2014) “Assessment of Climate Change over South America under RCP 4.5 and 8.5 Downscaling Scenarios" American Journal of Climate Change $3 / 5 \mathrm{p}: 15$

Demir, Ö. Atay, H., Eskioğlu O., Tuvan A., Demircan, M., Akçakaya, A. (2013). “RCP4.5 Senaryosuna Göre Türkiye'de Sıcaklık ve Yağış Projeksiyonları" III. Türkiye İklim Değişikliği Kongresi, TiKDEK, Konferans Dokümanı, 1-7.

Demircan, M., Demir, Ö., Atay, H., Eskioğlu, O., Yazıcı, B., Gürkan, H., Tuvan, A., Akçakaya, A., (2014a) "Yeni Senaryolara Göre Türkiye Akarsu Havzalarında İklim Değişikliği Projeksiyonları" TÜCAUMVIII. Coğrafya Sempozyumu Konferans Dokümanı 11-20.

Demircan, M., Demir, Ö., Atay, H., Eskioğlu, O., Yazıcı, B., Gürkan, H., Tuvan, A., Akçakaya, A., (2014b) “Türkiye'de Yeni Senaryolara Göre İklim Değişikliği Projeksiyonları". TÜCAUM-VIII. Coğrafya Sempozyumu Konferans Dokümanı 1-10.

Efe, B., Toros, H., Deniz, A. (2015) “Türkiye Geneli Yağış ve Sıcaklık Verilerinde Eğilimler ve Salınımlar" VII. Atmospheric Science Symposium, 28-30 April 2015, Bildiri Dokümanı.

Gampe, D., Nikulin, G., Ludwig, R. (2016) “Using an ensemble of regional climate models to assess climate change impacts on water scarcity in European river basins". Science of the Total Environment 573 pp:1503-1518

Gönençgil, B., İçel, G. “Türkiye'nin Doğu Akdeniz Kıyılarında Yıllık Toplam Yağışlarda Görülen Değişimler (1975-2006)". Türk Coğrafya Dergisi, 55 s.1-12, İstanbul.

Gürkan, H., Arabacı, H., Demircan, M., Eskioğlu, O, Şensoy, S., Yazıcı, B. (2016) "GFDL-ESM2M Modeli Temelinde RCP 4.5 ve RCP 8.5 Senaryolarına Göre Türkiye için Sıcaklık ve Yağış Projeksiyonları" Coğrafi Bilimler Dergisi 14(2), s.77-88.IPCC Climate: Observations, Projections and Impacts (Turkey), 2011.

IPCC (2014) Climate Change 2014 Synthesis Report.

İklim Değişikliğinin Su Kaynaklarına Etkisi Proje Dokümanı IDSKE, EK4Marmara Havzası (2016) T.C. Orman ve Su İşleri Bakanlığı, Su Yönetimi Genel Müdürlüğü, Ankara, Türkiye.

İklim Değişikliğinin Su Kaynaklarına Etkisi Proje Dokümanı IDSKE, EK6Kuzey Ege Havzası (2016) T.C. Orman ve Su İşleri Bakanlığı, Su Yönetimi Genel Müdürlüğü, Ankara, Türkiye.

Ji-Woo Lee, Song-You Hong, Eun-Chul Chang, Myoung-Seok Suh, Hyun-Suk Kang (2014) "Assessment of future climate change over East Asia due to the RCP scenarios downscaled by GRIMs-RMP" Climate Dynamics 42/3 pp.733-747.

Karabulut, M., Cosun, F. "Kahramanmaraş ilinde Yağışların Trend Analizi (2009). Coğrafi Bilimler Dergisi (1) s.65-83.

Ölgen, M.K. (2010) “Türkiye'de Yıllık ve Mevsimsel Yağış Değişkenliğinin Alansal Dağılımı" Ege Coğrafya Dergisi 19/1 s.85-95

Önol, B., Ünal, Y.S., Dalfes, H.N. (2009) “iklim Değişimi Senaryosunun Türkiye Üzerindeki Etkilerinin Modellenmesi”. iTÜdergisi/d, 8(5), s.169-177.

Öztürk T., Türkeş, M, Kurnaz, M.L. (2011) “RegCM4.3.5 İklim Modeli Benzetimleri Kullanılarak Türkiye'nin Gelecek Hava Sıcaklığı ve Yağış Klimatolojilerindeki Değişikliklerin Çözümlenmesi, Ege Coğrafya Dergisi, 20/1 s.17-27

Sarış, F., 2006. "Türkiye'de Yağış Yoğunluğunun Alansal ve Zamansal Değişimi “, Çanakkale Onsekiz Mart Üniversitesi Sosyal Bilimler Enstitüsü Coğrafya Anabilim Dalı Yayımlanmamış Yüksek Lisans Tezi, Çanakkale.

Sarış, F., Hannah, M.D., Eastwood, J.W., 2010. “Changes in Precipitation and River Flow in Northeast Turkey: Associations With the North Atlantic Oscillation" Sixth World Friend Conference, (October, 2010), Fez, Morocco

Sütgibi, S. (2015) “Büyük Menderes Havzasının Sıcaklık, Yağı̧ ve Akım değerlerindeki değişimler ve eğilimler" Marmara Coğrafya Dergisi 31/1, s.398-414.

Şen, Ö.L., Bozkurt, D., Göktürk, O. M., Dündar, B., Altürk B. (2013) “Türkiye'de İklim değişikliği ve Olası Etkileri” 3. Taşkın Sempozyumu'nda sunulmuştur. İstanbul, Türkiye. 
Tatlı, H., Dalfes N., Menteş, Ş.S. (2004) "Statistical Downscaling Method for Monthly Total Precipitation over Turkey. International Journal of Climatology (24) s.161-180

Turp, M.,T., Öztürk, T., Türkeş, M., Kurnaz, M.L, (2014) “RegCM4.3.5 Bölgesel İklim Modelini Kullanarak Türkiye ve Çevresi Bölgelerin Yakın Gelecekteki Hava Sıcaklığı ve Yağış Klimatolojileri için Öngörülen Değişikliklerin Incelenmesi" , Ege Coğrafya Dergisi, 23/1, 124.

Türkeş, M., 1996. "Spatial and Temporal Analysis of Annual Rainfall Variations in Turkey", International Journal of Climatology, 16, s.1057-1076.

Türkeş, M., Deniz, Z. (2011) “Climatology of South Marmara Division (North West Anatolia) and observed variations and trends. Journal of Human Sciences 8/1.

Türkiye İklim Değişikliği 6. Bildirimi (2016) T.C. Çevre ve Şehircilik Bakanlığı, Ankara. s.1-270

Türkoğlu N., Aydın, O., Duman, N., Çiçek, İ. (2016) “Türkiye'de Yağışın Farklı Mekansal Enterpolasyon Yöntemleriyle Karşılaştırılması" International Journal of Human Sciences, 13/3, 5637-5659.

Wang, X., Huang, G., Baetz, B. W. (2016) “Dynamically-downscaled probabilistic projections of precipitation changes: A Canadian case study" Environmental Research. 148 pp:86-101. 